\title{
Dexmedetomidine as an adjunct in laparoscopic surgery along with entropy as a tool to measure the anaesthetic depth
}

\author{
Shivani Bakshi ${ }^{1}$, Madhusudan Upadya ${ }^{2}$, Julie CR Misquith ${ }^{3 *}$ \\ Consultant Anaesthesiologist ${ }^{l}$, Kottayam Charitas Hospital, Kerala, India, Professor ${ }^{2}$, Associate \\ Professor ${ }^{3 *}$, Kasturba Medical College, Mangalore, Manipal Academy of Higher Education, \\ Karnataka, India
}

\begin{abstract}
Introduction: Dexmedetomidine is a drug that can be used for various anaesthetic indications such as an adjuvant for general anaesthesia and regional blocks, in premedication, as a hypnotic and analgesic postoperatively.
\end{abstract}

\begin{abstract}
Aim: To study the effect of dexmedetomidine as an adjuvant in anaesthesia for laparoscopic surgery using entropy as an instrument to monitor the anaesthetic depth.

Methods and materials: Sixty patients were enrolled for the study, thirty receiving dexmedetomidine infusion (group 1) and thirty receiving saline infusion (group 2). Prior to induction, an entropy sensor was positioned as per manufacturer's recommendation. Patients received a loading dose of given drug, either dexmedetomidine or saline, followed by an infusion for maintenance. All patients were given general anaesthesia with propofol and fentanyl. The given drug infusion was continued until extubation.
\end{abstract}

Results: Mean systolic and diastolic blood pressure during extubation showed 5\% and 8.5\% increase respectively from baseline in the dexmedetomidine group $(\mathrm{p}>0.050)$ as compared to $19 \%$ and $15 \%$ increase respectively in the saline group which was significant $(p<0.05)$. The dose of propofol used was reduced significantly; mean dose requirement for induction was $59 \pm 22.07$ in group 1 as compared to $97.74 \pm 27.044$ in group 2 . There was marked reduction in the opioid requirement intraoperatively in group $1(21.66 \pm 27.64)$ as compared to group 2 $(41.613 \pm 28.384)$ with adequate depth of anaesthesia (DOA) maintained.

Conclusion: Dexmedetomidine is an effectual anaesthetic adjunct that can be used in laparoscopic surgeries with an excellent recovery profile and provides adequate depth of anaesthesia.

Keywords : depth of anaesthesia; propofol; opioid; entropy; monitor; dexmedetomidine

\section{Introduction}

Anaesthesiologists require to provide adequate depth of anaesthesia (DOA) in laparoscopic surgeries because these surgeries most particularly are associated with increased blood pressure (BP) and systemic vascular resistance. $^{1}$ Dexmedetomidine has wide applications in anaesthesia.
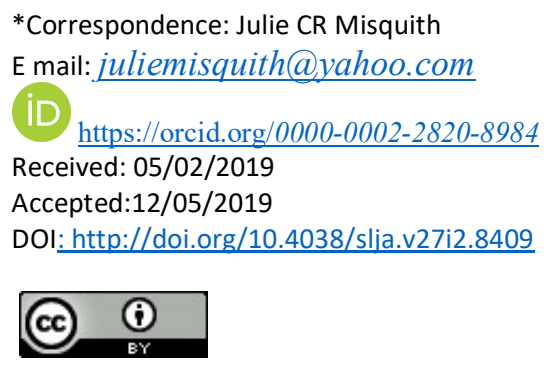

It can be used for effective premedication, attenuation of the laryngoscopic response and prevention of emergence delirium. ${ }^{2}$ It also provides superior analgesia after surgery and decrease in opioid requirements. ${ }^{3,4}$ It has minimum alveolar concentration (MAC) sparing properties ${ }^{5}$, decreases the incidence of postoperative nausea and vomiting (PONV), reduces metabolic demand of oxygen postoperatively which is helpful in cardiac patients and attenuates post-operative shivering. ${ }^{6}$

The sedative properties of dexmedetomidine is from the site of action in locus ceruleus. ${ }^{7,8}$ Its sympatholytic effect which results in hypotension and bradycardia is mainly due to the activation of post-synaptic $\alpha 2$ receptors, thus reducing the release of catecholamines. ${ }^{9}$ 
In this study, dexmedetomidine in laparoscopic surgeries and its effects on haemodynamic response, analgesic and anaesthetic requirement was observed. To prevent under dosing of anaesthetic drugs causing awareness under anaesthesia entropy was included as a monitoring tool.

The entropy monitor generates two indices, one reflects the cortical activity, the state entropy (SE), and the response entropy (RE) includes frontal electromyography (EMG) activity..$^{10}$ When patient is responding to an external stimulus like pain an EMG signal suddenly appears ${ }^{11}$ which alerts the anaesthesiologist to deepen the DOA. Normalizing both SE and RE is advantageous because when EMG power becomes zero SE will be the same as RE. RE ranges from zero to hundred and SE from zero to ninety-one. Lower values (40-60) indicate deeper levels of depth of anaesthesia. ${ }^{12,13}$

Our objectives were to determine

1. Whether dexmedetomidine would be an effective adjunct with respect to decrease in the anaesthetic requirements?

2. To assess effect of dexmedetomidine on the haemodynamics.

3. Does dexmedetomidine have propofol and opioid sparing action (depth maintained with entropy)?

\section{Methods and Materials}

This was a prospective cohort observational study conducted in hospitals of Kasturba Medical College. Study duration was from September 2012 to August 2014. After Institutional Ethics Committee (IEC) approval, 60 patients of American Society of Anaesthesiologists (ASA) grade I and II, between 18 to 60 years of age, posted for surgery under general anaesthesia were enrolled. 30 patients in each group was the required sample size calculated at a power of $90 \%$ and a confidence level of $95 \%$ based on a previously published data. ${ }^{1}$ Laparoscopic surgeries included cholecystectomy, appendicectomy and laparoscopic adhesiolysis. Exclusion criteria was patient refusal, III/IV ASA grade, any contraindication to the use of dexmedetomidine e.g. bradycardia, hypotension, ventricular dysfunction, cardiac failure, heart blocks, renal or liver disorder, history of head injury, patients with neurologic disorders, substance abuse, patients on anticholinergic, clonidine medications and any scalp or skull deformities A valid written informed consent was obtained from patients posted for laparoscopic surgery under general anaesthesia. The infusion of the given drug was prepared in normal saline. Dexmedetomidine group (Group 1) in the concentration of $4 \mu \mathrm{g} / \mathrm{ml}$ and the other was with plain normal saline (Group 2). Groups were allotted by the sealed envelope technique. Baseline monitors like noninvasive blood pressure (NIBP), oxygen saturation $\left(\mathrm{SpO}_{2}\right)$, electrocardiogram (ECG) and entropy were attached. As recommended by the manufacturer, the forehead was wiped with spirit and an Entropy Sensor (Entropy Sensor, GE Healthcare) was attached. While the patient was awake the bio signal from the patient's forehead was recorded. Before induction, the impedance was noted and a value below $7.5 \mathrm{k}$ was acceptable. The preinduction values of $\mathrm{RE}$ and $\mathrm{SE}$, pulse oximetry, heart rate (HR) and blood pressure (BP) were noted. Loading dose of either dexmedetomidine or saline of $1 \mu \mathrm{g} / \mathrm{kg}$ infusion was given over 15 minutes and then maintained at $0.2 \mu \mathrm{g} / \mathrm{kg} / \mathrm{h}$. All patients were given general anaesthesia with premedicants midazolam $0.02 \mathrm{mg} / \mathrm{kg}$ and $1.5 \mu \mathrm{g} / \mathrm{kg}$ fentanyl intravenously. Induction was done with $5 \mathrm{mg}$ IV titrated doses of propofol until the entropy value of $40-60$ was reached. $1 \mathrm{mg} / \mathrm{kg}$ i.v. rocuronium was used as muscle relaxant. Haemodynamic response to direct laryngoscopy and endotracheal intubation was noted. Oral intubation was done, and placement confirmed with bilateral equal air entry and end-tidal carbon dioxide $\left(\mathrm{EtCO}_{2}\right)$ trace. Anaesthesia was maintained with oxygen, nitrous oxide $\left(\mathrm{N}_{2} \mathrm{O}\right)$ mixture $(60: 40)$, and sevoflurane to attain MAC of 1 and vecuronium top ups was used as muscle 
relaxant. Intraoperative anaesthetic requirement was gauged by $\mathrm{HR}$ and $\mathrm{BP}$, end point for requirement for both was considered a $20 \%$ increase from baseline value, and $\mathrm{SE}$ value, while the analgesic requirement was titrated with $\mathrm{RE}$, with an aim to maintain both RE and SE around 4060. Whenever required, propofol $10 \mathrm{mg}$ boluses were given to deepen the plane of anaesthesia. Analgesia was repeated according to RE in the form of fentanyl top ups of $10 \mu \mathrm{g}$. The given drug infusions were continued until extubation. Neuromuscular relaxant was reversed with neostigmine $0.05 \mathrm{mg} / \mathrm{kg}$ and glycopyrrolate $0.01 \mathrm{mg} / \mathrm{kg}$. Extubation response with respect to HR and BP was documented. At the end of surgery, paracetamol $1 \mathrm{~g}$ i.v. was given for postoperative analgesia. Any adverse effects like bradycardia, hypotension, PONV and respiratory depression were noted. After two hours of observation in the recovery room, patients were shifted to the ward.

\section{Statistical analysis}

30 patients in each group was the required sample size calculated at a power of $90 \%$ and a confidence level of $95 \%$ based on a previously published data. ${ }^{1}$ Statistical package for the Social Sciences (SPSS) 17 (SPSS Inc., Chicago, Illinois, USA) was used to do the analysis. Chi-square test was used for parametric values. Students unpaired ' $t$ ' test was used to determine a statistical difference between the groups. In the above tests, the 'p' value of less than 0.05 was indicative of statistical significance.

\section{Results}

The difference of proportions of subjects observed between the study groups with respect to ASA physical status, age, weight, BMI and sex was comparable. (Table 1,2,3)
Table 1: Age, weight and BMI distribution in each group

\begin{tabular}{|l|l|l|l|l|}
\hline Group & $\mathrm{N}$ & $\begin{array}{l}\text { Mean Age } \\
\text { (in years) }\end{array}$ & Weight (in kgs) & BMI \\
\hline Group1 & 30 & $38.01 \pm 10.92$ & $61.63 \pm 11.97$ & $24.83 \pm 4.81$ \\
\hline Group2 & 31 & $35.517 \pm 10.64$ & $57.22 \pm 13.10$ & $24.35 \pm 4.90$ \\
\hline P value & & $\mathrm{P}=0.372$ & $\mathrm{P}=0.176$ & $\mathrm{P}=0.706$ \\
\hline
\end{tabular}

Values expressed as mean $\pm \mathrm{SD}$

Table 2: Sex distribution in each group

\begin{tabular}{|c|c|c|c|}
\hline & Group1 & Group2 & Total \\
\hline $\begin{array}{l}\text { Female } \\
\text { count } \%\end{array}$ & $\begin{array}{l}22 \\
73.3 \%\end{array}$ & $\begin{array}{l}25 \\
80.6 \%\end{array}$ & $\begin{array}{l}47 \\
77 \%\end{array}$ \\
\hline $\begin{array}{l}\text { Male } \\
\text { count\% }\end{array}$ & $\begin{array}{l}8 \\
26.7 \%\end{array}$ & \begin{tabular}{|l}
6 \\
$19.4 \%$
\end{tabular} & $\begin{array}{l}14 \\
23 \%\end{array}$ \\
\hline $\begin{array}{l}\text { Total } \\
\text { count } \%\end{array}$ & \begin{tabular}{|l}
30 \\
$100 \%$
\end{tabular} & \begin{tabular}{|l}
31 \\
$100 \%$
\end{tabular} & $\begin{array}{l}61 \\
100 \%\end{array}$ \\
\hline
\end{tabular}

Chi square value $=0.461, \mathrm{df}-1, \mathrm{p}$ value0.497

Table 3: ASA distribution in each group

\begin{tabular}{|l|l|l|l|}
\hline & Group1 & Group2 & Total \\
\hline ASA I & 14 & 18 & 32 \\
count $\%$ & $46.7 \%$ & $58.1 \%$ & $52.4 \%$ \\
\hline ASAll & 16 & 13 & 29 \\
count $\%$ & $53.3 \%$ & $41.9 \%$ & $47.5 \%$ \\
\hline Total \\
count $\%$ & 30 & 31 & 61 \\
\hline
\end{tabular}

Table 4: Requirement of anaesthetic agents

\begin{tabular}{|l|l|l|l|l|}
\hline & group & $\mathrm{N}$ & Mean \pm SD & $\mathrm{P}$ value \\
\hline $\begin{array}{l}\text { Induction - } \\
\text { propofol }\end{array}$ & Group1 & 30 & $59.00 \pm 22.03$ & \\
\cline { 2 - 5 } & Group2 & 31 & $97.74 \pm 27.04$ & $<0.001$ \\
\hline \multirow{2}{*}{$\begin{array}{l}\text { NMB } \\
\text { rocuronium }\end{array}$} & Group1 & 30 & $53.00 \pm 10.22$ & \\
\cline { 2 - 5 } & Group2 & 31 & $50.80 \pm 9.32$ & $=0.384$ \\
\hline $\begin{array}{l}\text { NMB } \\
\text { vecuronium }\end{array}$ & Group1 & 28 & $1.57 \pm 1.93$ & \\
\cline { 2 - 5 } $\begin{array}{l}\text { Maintenance- } \\
\text { propofol }\end{array}$ & Group2 & 29 & $1.20 \pm 1.78$ & $=0.462$ \\
\cline { 2 - 5 } & Group2 & 31 & $36.80 \pm 46.08$ & \\
\hline Fentanyl top & Group1 & 30 & $21.66 \pm 27.64$ & \\
\cline { 2 - 5 } up & Group2 & 31 & $41.61 \pm 23.38$ & $=0.007$ \\
\hline
\end{tabular}


The mean induction dose requirement of propofol was $59 \pm 22.07$ in group 1 as compared to $97.74 \pm 27.044$ in group 2 . The dose of propofol intraoperatively for adequate anaesthetic depth was also decreased in group1 as compared to group 2 with statistical significance. There was marked reduction in the opioid requirements intraoperatively in group1 $(21.66 \pm 27.64)$ as compared to group $2(41.613 \pm 28.384)$. The difference of proportions of subjects observed between the two groups with respect to neuromuscular agent, vecuronium, used was not statistically significant. $(\mathrm{t}=$ $0.741, \mathrm{p}=0.462)($ Table 4$)$

Figure 1: Systolic blood pressure variability of two groups at different time periods

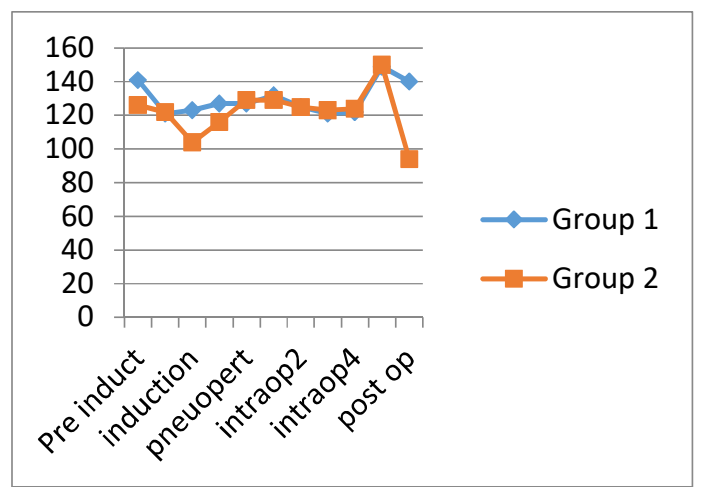

The mean blood pressure at start was elevated in group 1 than group 2. There was $14 \%$ reduction in the mean systolic blood pressure after loading dose of dexmedetomidine which was highly significant as compared to $3 \%$ reduction in the saline group. After that minimal change was observed for entire duration of infusion. Mean systolic BP at intubation, at creation of pneumoperitoneum, every 15 min intraoperatively, at extubation and post extubation in group 1 was found to be $127.27 \pm 25.388,127 \pm 25.4,132 \pm$ $23.403,149.90 \pm 14.430,140.10 \pm 16.875$ respectively whereas that of group 2 at same time intervals was $116.740 \pm 20.115,129.23$ $\pm 23.40,129.74 \pm 21.407,150.65 \pm 25.292$, $133.06 \pm 16.63$, respectively and the difference was not found to be statistically significant $(\mathrm{p}>0.050)$. There was good control of systolic blood pressure during laryngoscopy, with minimal or no change in systolic blood pressure with pneumoperitoneum in both the groups. Mean systolic blood pressure during extubation increased from $141.70 \pm 20.84$ to $149.90 \pm$ 14.430 i.e. $5 \%$ increase in the dexmedetomidine group from the baseline which was not significant $p>0.050$ as compared to $19 \%$ increase in the saline group i.e. from $126 \pm 20.77$ to $150.65 \pm 25.292$ which was highly significant $\mathrm{p}<0.050$. (Figure 1)

Figure 2: Diastolic blood pressure variability of two groups at different time periods

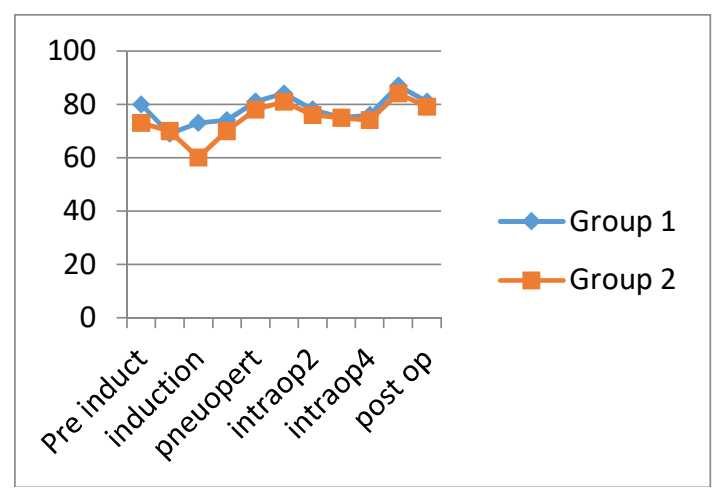

The mean diastolic blood pressure at start was higher in groupl $(80.7 \pm 10.07)$ as compared to group $2(73.19 \pm 11.38)$. There was $14.4 \%$ reduction in the mean diastolic blood pressure after loading dose of dexmedetomidine which was highly significant as compared to $3.7 \%$ reduction in the saline group. After that minimal change was observed for entire duration of infusion. Mean diastolic blood pressure at intubation, at creation of pneumoperitoneum, every 15 min intraoperatively, at extubation and post extubation in group 1 was found to be 74.07 $\pm 15.909,81.27 \pm 16.758,84.13 \pm 15.462$, $87.57 \pm 9.863,81.87 \pm 10.559$ respectively whereas that of group 2 at same time intervals was $70.13 \pm 11.427,78.06 \pm 13.434,81.03 \pm$ $12.582,84.48 \pm 14.980,79.23 \pm 10.379$, respectively and the difference was not found to be statistically significant ( $p>0.050)$. Mean diastolic blood pressure during extubation increased from $80.70 \pm 10.07$ to $87.57 \pm 9.86$ i.e. $8.5 \%$ increase in the 
dexmedetomidine group which was not statistically significant as compared to $15 \%$ increase in the saline group i.e. from $73.19 \pm$ 11.38 to $84.48 \pm 14.980$ which was statistically significant $p<0.050$. (Figure 2 )

Figure 3: Heart rate variability of two groups at different time periods

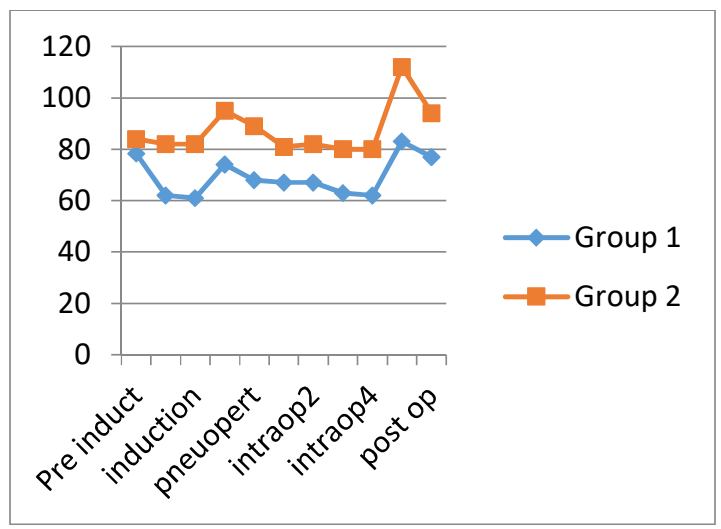

Mean HR on starting was $78.27 \pm 11.03$ which fell to $62.07 \pm 13.50 ; \mathrm{p}<0.001$ i.e. $20 \%$ reduction in the Group 1in comparison to $1.6 \%$ reduction Group 2. There was a fall in $\mathrm{HR}$ at beginning in Group 1. Mean heart rate at intubation, at creation of pneumoperitoneum, every $15 \mathrm{~min}$ intraoperatively, at extubation and post extubation was found to be $\mathrm{p}<0.050$ between groups 1 and 2. There was good control of HR during laryngoscopy, with minimal or no change with pneumoperitoneum and during extubation in the group 1 while increase in the mean HR during intubation and extubation was noted in Group 2. (Figure 3)

\section{Discussion}

As already known, dexmedetomidine potentiates anaesthetic effects of all intraoperative anaesthetics. It causes profound reduction in anaesthetic requirement as shown to be mediated through central $\alpha_{2}$ adrenergic receptors. A study conducted in 2012 by Poonam S Ghodki et al ${ }^{1}$ observed a $62.5 \%$ decrease in the propofol induction dose with the use of dexmedetomidine. Findings are similar in this study in which we observed a $39.6 \%$ induction dose reduction of propofol in the dexmedetomidine group. We also observed a reduction in the intra operative requirements of propofol to maintain adequate depth of anaesthesia i.e. entropy between 40-60 i.e. from $36.80 \pm 46.08$ in the dexmedetomidine group as compared to $53.83 \pm 41.07$ in saline group showing no statistical significance. Anne Vakkuri et $\mathrm{al}^{12}$ found that during the entire anaesthesia period, propofol usage was lesser in the group where entropy was monitored particularly in the last $15 \mathrm{~min}$. ( $p<$ $0.001)$

Ghodki et al study also showed reduced requirement of inhalation that is isoflurane (25\%-35\%) reduction, however, in this study we kept MAC at 1 maintaining dial concentration of sevoflurane between 1-2\% constant for both the groups.

Studies done ${ }^{14,15}$ on how dexmedetomidine blunts the vasopressor response to tracheal intubation and anaesthetic requirement perioperatively, observed that there was significant anaesthetic and opioid sparing effect. In our study there was good control of systolic and diastolic blood pressures during laryngoscopy, with minimal or no change in blood pressures with pneumoperitoneum in both the groups. However, mean SBP during extubation showed a 5\% elevation in the group dexmedetomidine from the baseline to a $19 \%$ increase in the saline group. Mean DBP during extubation showed an $8.5 \%$ increase in the dexmedetomidine group when compared to $15 \%$ increase in the saline group There was good control of HR during laryngoscopy, with minimal or no change with pneumoperitoneum and extubation in the dexmedetomidine group but there was a substantial increase in the mean HR during intubation and extubation in the saline group. In the saline group the pressor response was attenuated by giving additional top up of propofol and fentanyl to deepen the plane of anaesthesia. Hence opioid requirement intraoperatively was much higher in the saline group than in the dexmedetomidine group i.e. there was about $49 \%$ increase in the 
requirement of fentanyl with respect to the dexmedetomidine group. $(p=0.007)$

Respiratory depression is much less with dexmedetomidine than other sedatives and due to this property, dexmedetomidine infusion can be continued safely through extubation while other sedative agents often necessitate their stoppage during extubation period. ${ }^{8}$ However, in our study, no episodes of respiratory depression was seen in any patients in the post-operative period. The difference of proportions of subjects observed between the two groups with respect to $\mathrm{SpO}_{2}$, respiratory rate and $\mathrm{EtCO}_{2}$ was not statistically significant, at the starting of the surgery, and also intra operatively $(\mathrm{p}>0.05)$.

Dexmedetomidine is shown to have a better recovery profile. On awakening, patients return to their initial level of consciousness. ${ }^{16}$ Our results suggest that the entropy monitor reliably indicates the level of dexmedetomidine-induced sedation although it produces hypnosis similar to physiological sleep. This was substantiated by Hall et al. ${ }^{4}$ using bispectral index (BIS) monitoring system and psychometric tests.

\section{Conclusion}

From this study we conferred that dexmedetomidine can be used as an anaesthetic adjuvant which decreases the requirement of anaesthetics and opioids as seen by the decrease in the dose of propofol and fentanyl used during the surgery. We also conclude that dexmedetomidine attenuates sympathoadrenal response and maintains desirable haemodynamics. Using entropy helped maintain effective anaesthetic depth with an excellent recovery profile.

\section{Limitations of the Study}

This study was limited to a small population included in two medical academic centres. We did not study the effect of dexmedetomidine on inhalational requirement and we kept MAC constant for both the groups. Monitoring depth of anaesthesia only may result in under dosing analgesic requirement and further studies are required to substantiate these findings.

Haemodynamic disturbances in laparoscopic surgery are multifactorial. After induction of anaesthesia it could be due to surgical stimulation, peritoneal stretching, effects of pneumoperitoneum and increase abdominal pressures, patient positioning and hypercarbia among other reasons. Depth of anaesthesia monitoring is used to prevent accidental awareness.

\section{References}

1. Ghodki PS, Thombre SK, Sardesai SP, Harnagle $\mathrm{K}$. Dexmedetomidine as an anesthetic adjuvant in laparoscopic surgery: An observational study using entropy monitoring. Journal of Anaesthesiol Clin Pharmacol 2012; 28:334-8. https://doi.org/10.4103/0970-9185.98329 PMid:22869940 PMCid:PMC3409943

2. Afsani N. Clinical application of dexmedetomidine. S Afr J AnaesthesiolAnalg. 2010; 16:50-6. https://doi.org/10.1080/22201173.2010.10872681

3. Aho M, Lehtinen AM, Erkola O, Kallio A, Korttila K. The effect of intravenously administered dexmedetomidine on perioperative hemodynamics and isoflurane requirements in patients undergoing abdominal hysterectomy. Anesthesiology. 1991; 74:997-1002. https://doi.org/10.1097/00000542-199106000$\underline{00005}$

PMid: 1675042

4. Hall JE, Uhrich TD, Barney JA, Arain SR, Ebert TJ. Sedative, amnestic, and analgesicproperties of small dose dexmedetomidine infusions. AnesthAnalg 2000; 90:699-705.

https://doi.org/10.1097/00000539-200003000$\underline{00035}$

PMid: 10702460

5. Aho MS, Erkola OA, Scheinin H, Lehtmen AM. Effect of intravenously administered dexmedetomidine on pain after laparoscopic tubal ligation. AnesthAnalg 1991; 73:112-8. https://doi.org/10.1213/00000539-199108000$\underline{00002}$ PMid: 1854025

6. Grosu I, Lavand'homme P. Use of dexmedetomidine for pain control. Med Rep. 2010; 2:90.

https://doi.org/10.3410/M2-90

PMid:21283652 PMCid:PMC3026617

7. Guo TZ, Jiang JY, Buttermann AE, Maze M. Dexmedetomidine injection into the locus ceruleus produces antinociception. Anesthesiology. 1996; 84:873-81. 
https://doi.org/10.1097/00000542-199604000$\underline{00015}$

PMid:8638842

8. Carollo DS, Nossaman BD, Ramadhyani U. Dexmedetomidine: A review of clinical applications. Curr Opin Anaesthesiol. 2008; 21:457-61.

https://doi.org/10.1097/ACO.0b013e328305e3ef PMid: 18660652

9. Ishii H, Kohno T, Yamakura T, Ikoma M, Baba H. Action of dexmedetomidine on the substantia gelatinosa neurons of the rat spinal cord. Eur J Neurosci. 2008; 27:3182-90

https://doi.org/10.1111/j.14609568.2008.06260.x

PMid:18554299 PMCid:PMC2658019

10. Maksimow A, Snapir A, Sarkela M, et al. Assessing the depth of dexmedetomidine-induced sedation with electroencephalogram (EEG)based spectral entropy. Acta AnaesthesiologicaScandinavica 2006; 51: 1: 2231.

https://doi.org/10.1111/j.13996576.2006.01174.x

PMid: 17073855

11. Vanluchene AL, Struys MM, Heyse BE, Mortier EP. Spectral entropy measurement of patient responsiveness during propofol and remifentanil. A comparison with the bispectral index. $\mathrm{Br} \mathrm{J}$ Anaesth 2004; 93:645-54.

https://doi.org/10.1093/bja/aeh251

PMid:15321934

12. Vakkuri A, Yli-Hankala A, Sandin R et al. Spectral entropy monitoring is associated with reduced propofol use and faster emergence in propofol-nitrous oxide-alfentanil anesthesia. Anesthesiology 2005; 103:274-9.

https://doi.org/10.1097/00000542-200508000$\underline{00010}$

PMid:16052109

13. Vanluchene AL, Struys MM, Heyse BE, Mortier EP. Spectral entropy measurement of patient responsiveness during propofol and remifentanil. A comparison with the bispectral index. $\mathrm{Br} \mathrm{J}$ Anaesth 2004; 93:645-

https://doi.org/10.1093/bja/aeh251

PMid:1532193454.

14. Keniya VM, Ladi S, Naphade R. Dexmedetomidine attenuates sympathoadrenal response to tracheal intubation and reduces perioperative anaesthetic requirement. Indian Journal of Anaesthesia. 2011; 55:352-357. https://doi.org/10.4103/0019-5049.84846 PMid:22013250 PMCid:PMC3190508

15. Mondal S, Mondal H, Sarkar R, Rahaman M. Comparison of dexmedetomidine and clonidine for attenuation of sympathoadrenal responses and anesthetic requirements to laryngoscopy and endotracheal intubation. International Journal of Basic and Clinical Pharmacology. 2014;3:501-
506.

https://doi.org/10.5455/23192003.ijbcp20140617

16. Pandit JJ, Andrade J, Bogod DG, et al. 5th National Audit project (NAPS) on accidental awareness during general anaesthesia: summary of main findings and risk factors. Anaesthesia 2014; 69: 1089-101.

https://doi.org/10.1111/anae.12826

PMid:25204236 